\title{
Bothersome lower urinary symptoms during pregnancy: a preliminary study using the International Consultation on Incontinence Questionnaire
}

\author{
*Adaji SE, Shittu OS, Bature SB, Nasir S, Olatunji O \\ Urogynaecology Unit, Department of Obstetrics and Gynaecology, ABU Teaching Hospital Zaria, Nigeria
}

\begin{abstract}
Background: During pregnancy, many women suffer from lower urinary tract symptoms which they hardly report to their care providers. Measuring the prevalence of these symptoms has been difficult because of lack of uniform nomenclature and standardized tool. The updated nomenclature and the new ICIQ-FLUTS questionnaire offer an opportunity for assessment of these symptoms especially in developing countries.

Objective: This study aimed to establish the prevalence of bothersome lower urinary symptoms among pregnant women in Zaria, Nigeria.

Methods: This was a cross-sectional study in which the International Consultation on Incontinence Questionnaire on Female Lower Urinary Tract Symptoms (ICIQ-FLUTS) was administered by trained interviewers to 204 consenting pregnant women aged 15 to 42 years who were attending Antenatal care (ANC) at a tertiary health facility in Zaria, Nigeria.

Results: Storage phase symptoms (nocturia, urgency, daytime frequency and painful bladder) were common among respondents. Of these, nocturia was the commonest with $94.1 \%$ of the respondents reporting it. Voiding symptoms (hesitancy, straining to pass urine and interrupted stream) were also found. Interrupted stream was the commonest of these, occurring in $8.3 \%$ of respondents. Incontinence; stress (13.7\%), urge (9.8\%) and enuresis $(1 \%)$ were found among the respondents.

Conclusions: These findings show that diverse, bothersome forms of lower urinary tract symptoms are experienced by pregnant women in this environment and the ICIQ-FLUTS questionnaire is a helpful tool in identifying these symptoms. Key Words: Lower urinary tract symptoms, Pregnancy, ICIQ-FLUTS Questionnaire, Zaria, Nigeria

African Health Sciences 2011; 11(S1): S46 - S52
\end{abstract}

\section{Introduction}

Many women experience lower urinary tract symptoms during pregnancy, which they may find distressing and disabling. The prevalence of these symptoms varies widely depending on the terminologies and definitions used in relation to lower urinary tract complaints as well as the study population and design.

In 2002, the International Continence Society (ICS), in its efforts to clarify and unify the language used in studies of lower urinary tract complaints, updated the definitions and terminologies used in relation to lower urinary tract dysfunction ${ }^{1}$. This has made epidemiological studies easier and facilitated the comparison and pooling of studies carried out in different settings. According to this update, lower

\begin{tabular}{|l|}
\hline *Correspondence author \\
Dr Sunday E Adaji \\
Urogynaecology Unit \\
Department of Obstetrics and Gynaecology \\
ABU Teaching Hospital Zaria \\
Nigeria \\
Tel: 08052587771 \\
Email: sonnyadaji@gmail.com \\
\hline
\end{tabular}

S46 urinary tract dysfunctions could be considered as a symptom, a sign, a urodynamic finding or as a condition $^{1,2}$.

Lower urinary tract symptoms (LUTS) are defined from the perspective of the patient and could occur during storage, voiding, and postmicturition. The symptoms could also occur in relation to sexual intercourse, pelvic organ prolapse, or as lower urinary tract pains and LUTD syndromes ${ }^{2}$.

The effect of pregnancy on lower urinary symptoms in women has for a long time been of interest to researchers. The anatomical and physiological changes affecting the lower urinary tract in pregnancy as well as the hormonal milleau of pregnancy have been postulated to underlie the pathogenesis of lower urinary symptoms in pregnancy ${ }^{3,4}$. The elevated levels of oestrogen and progesterone are known to make the bladder more squamous. The detrusor muscle undergoes hypertrophy and hypotonia with increased bladder capacity ${ }^{5}$. The bladder also undergoes anatomical changes favourable to lower urinary tract symptoms.

African Health Sciences Vol 11 Special Issue 1 August 2011 
Such changes include upwards and anterior displacement of the bladder, making it to become abdominal. Its base also enlarges and the trigone becomes more convex than concave. Distortion of the bladder by the uterus fundus in pregnancy has also been shown in radiological investigations ${ }^{6}$. Several studies have linked these anatomical changes in pregnancy with lower urinary tract symptoms. Thorp et al showed in a study of 123 pregnant women that mean daily urine output, mean number of voids per day increased with gestational age and declined after delivery, while episodes of urinary incontinence peaked in the third trimester of pregnancy and improved after birth ${ }^{7}$. Using the International Prostate Symptom Score (IPSS), Aslan et al found voiding symptoms were commoner among pregnant women than controls and that nocturia and frequency were the commonest LUTS among a cohort of 256 pregnant women in Turkey ${ }^{8}$. In a Taiwanese study using a LUTS questionnaire with 12 questions related to symptoms associated with urination, Sun et al showed that LUTS was common in pregnancy with nocturia, stress urinary incontinence and urgency as the commonest forms?.

Although many pregnant women in this environment have complaints related to their lower urinary tract functions, there has been little effort at quantification and characterization of these symptoms. Even in countries where these studies were done, there have been questions about the standards and the uniformity of the questionnaires and the absence of uniform guidelines for carrying out the studies. These have made it difficult to compare findings. This study which uses the internationally agreed terminologies and definitions, and the validated International Consultation on Incontinence LUTS Questionnaire $^{10,11}$ therefore fills a critical gap in knowledge with regard to LUTS in pregnancy in an entirely non-caucasian population and in a developing country setting.

The aim of this study was to determine the prevalence of bothersome lower urinary tract symptoms during pregnancy using the new ICI Female LUTS Questionnaire (ICIQ-FLUTS).

\section{Methods}

This was a descriptive, cross-sectional study in which 204 apparently healthy pregnant women attending routine $\mathrm{ANC}$ at the $\mathrm{ABU}$ Teaching Hospital in Zaria Nigeria were screened for lower urinary tract symptoms using the International Consultation on Incontinence Questionnaire on Female Lower Urinary Tract Symptoms (ICIQ-FLUTS) UK English Version. The ICIQ-FLUTS questionnaire is a tool of proven reliability and validity, designed and copy right protected by the International Consultation on Incontinence to assess the occurrence and severity of lower urinary tract symptoms and how bothersome the symptoms are to respondents. This questionnaire includes 13 questions related to lower urinary tract symptoms (LUTS) experienced within the 4 weeks preceding the survey, to which responses are made on a 5- category (0-4) scale depending on presence of symptom and perceived severity. The symptoms of interest were bladder storage phase symptoms, voiding phase symptoms and incontinence. The degree to which the subjects were bothered by the symptoms was assessed on an 11category scale $(0-10)$. This was later re-categorised into $4(0=$ not bothered, $1-3=$ mildly bothered, $4-$ $7=$ moderately bothered and $8-10=$ severely bothered) in order to obtain discrete categories. Staff providing antenatal care were trained on how to help the respondents (most of whom were not literate) to respond to the questionnaire by explaining the contents sometimes in simpler English or the local language (Hausa). During a period of one week in 2008, the interviewers administered the questionnaires daily, to consenting antenatal women. Before the commencement of the study ethical clearance was obtained from the Ethical Committee of the Ahmadu Bello University Teaching Hospital, Zaria, and only antenatal clients who gave their verbal consent were entered into the study. Data was analysed using SPSS Version 11.5 for Windows.

For the purpose of this study, the new ICS terminologies and definitions of lower urinary tract symptoms were adopted ${ }^{2}$

\section{Results \\ Demographic and obstetric characteristics}

The respondents' ages ranged from 15-42 years with a mean of 29.6 years and the majority of them were multiparous with a mean parity of 2 children per woman. Most (49.8\%) were in the second trimester of pregnancy, while $45.8 \%$ were in the third trimester; only $2 \%$ were in the first trimester of pregnancy. About $66 \%$ of the women had a previous vaginal delivery, with $3.9 \%$ remembering a perineal injury during a previous vaginal birth; $27.5 \%$ have had an episiotomy at a previous vaginal birth. 


\section{Storage phase symptoms}

The storage and voiding phase symptoms experienced by the respondents included nocturia, urgency, dysuria, and daytime frequency.

Nocturia
The prevalence of nocturia, defined as waking up to void one or more times at night was $94.1 \%$ in this study. Figure 1 shows the severity of this symptom (\% of number of times urine is voided each night).

Figure 1: Severity of nocturia among respondents

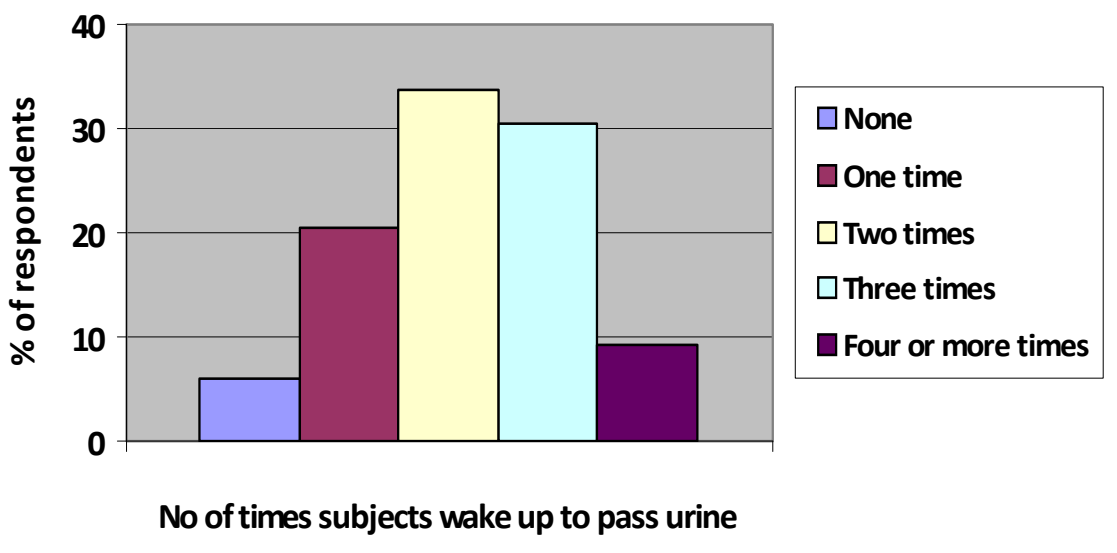

Urgency and Dysuria (pain in the bladder)

The prevalence of urgency urinary incontinence and dysuria were $27 \%$ and $20.1 \%$ respectively. Most of the women $(73 \%)$ had never had urgency while $20.1 \%$ had it occasionally, $6.4 \%$ sometimes and only $0.5 \%$ had most of the time. Dysuria (or pain in the bladder during micturition) was absent in $79.9 \%$ of the women, occurred occasionally in $15.2 \%$, sometimes in $3.4 \%$ and most of the time only in $1.5 \%$ of respondents.

\section{Daytime Frequency}

Among the 204 study subjects, 36 of them (17.6\%) had daytime frequency. Figure 2 below show the response to the question "How often do you pass urine during the day?"

Figure 2: Daytime voiding frequency among the respondents

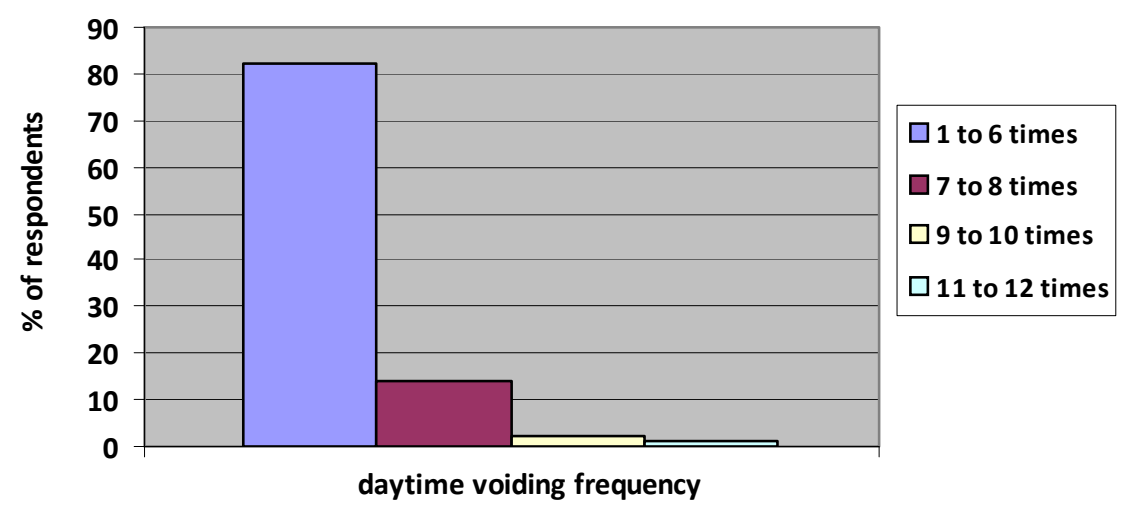

\section{Voiding symptoms}

In this study population, hesitancy had a prevalence rate of $6.9 \%$, straining to pass urine was at $3.9 \%$ and interrupted stream at $13.2 \%$ (table 1 ). 
Table 1: Occurrence of hesitancy, straining to pass urine and interrupted stream

\begin{tabular}{lllllr}
\hline Symptom & Never & Occasionally & Sometimes & Most of the time & All \\
\hline $\begin{array}{l}\text { Hesitancy } \\
\begin{array}{l}\text { Straining to } \\
\text { pass urine }\end{array}\end{array}$ & $190(93.1)$ & $10(4.9)$ & $3(1.5)$ & $1(0.5)$ & 204 \\
$\begin{array}{l}\text { Interrupted } \\
\text { stream }\end{array}$ & $177(86.8$ & $4(2.0)$ & $3(1.5)$ & $1(0.5)$ & 204 \\
\hline
\end{tabular}

Incontinence

The prevalence rate of urinary incontinence was 26.5

$\%$. Table 2 below shows the types of incontinence

found in this study population and the frequency of occurrence.

Table 2: Types of incontinence and their frequency of occurrence

\begin{tabular}{llllll}
\hline $\begin{array}{l}\text { Type of } \\
\text { incontinence }\end{array}$ & None & Occasionally & Sometimes & $\begin{array}{l}\text { Most of } \\
\text { the time }\end{array}$ & Total \\
\hline Urge incontinence & $184(90.2)$ & $15(7.4)$ & $4(2)$ & $1(0.5)$ & $204(100)$ \\
Stress & $176(86.3)$ & $17(8.3)$ & $10(4.9)$ & $1(0.5)$ & $204(100)$ \\
Nocturnal enuresis & $201(98.5)$ & $2(1)$ & $0(0.0)$ & $0(0.0)$ & $203(100)$ \\
Unexplained* & $200(98)$ & $2(1)$ & $2(1)$ & $0(0.0)$ & $204(100)$ \\
\hline
\end{tabular}

*Not adequately characterized by subjects

Pregnancy trimesters and lower urinary tract symptoms

As shown in table 3 below the type of symptoms experienced varied with trimester of pregnancy.

Table 3: LUTS and trimesters of pregnancy

\begin{tabular}{llll}
\hline Symptom & \multicolumn{3}{l}{ Trimester } \\
\cline { 2 - 4 } & $\begin{array}{l}\mathbf{1}^{\text {st }} \\
n=9\end{array}$ & $\begin{array}{l}\mathbf{2}^{\text {nd }} \\
n=101\end{array}$ & $\begin{array}{c}\mathbf{3}^{\text {rd }} \\
n=93\end{array}$ \\
Storage phase & & & \\
\hline Nocturia & 88.9 & 94.1 & 94.6 \\
Urgency & 22.2 & 27.7 & 25.8 \\
Bladder pains & 0 & 20.8 & 20.4 \\
Daytime freqency & 22.2 & 21.8 & 12.9 \\
Voiding phase & & & \\
Hesitancy & 0 & 3 & 10.8 \\
Straining & 11.1 & 2 & 5.4 \\
Interrupted str.eam & 11.1 & 11.9 & 15.1 \\
Incontinence & & & \\
Stress incontinence & 0 & 12.9 & 16.1 \\
Urge incontinence & 0 & 12.9 & 7.5 \\
\hline
\end{tabular}

\section{Effect of LUTS on study subjects}

The extent to which the subjects were bothered about their lower urinary tract symptoms as shown in table 4. Many of them found their symptoms bothersome. 
Table 4: Extent to which subjects perceived their symptoms to be bothersome

\begin{tabular}{llllll}
\hline Symptom & All cases & $\begin{array}{l}\text { Not } \\
\text { bothered }\end{array}$ & $\begin{array}{l}\text { Slightly } \\
\text { bothered }\end{array}$ & $\begin{array}{l}\text { Moderately } \\
\text { bothered }\end{array}$ & $\begin{array}{l}\text { Severely } \\
\text { bothered }\end{array}$ \\
\hline $\begin{array}{l}\text { Storage symptoms } \\
\text { Nocturia }\end{array}$ & $192(94.1)$ & $126(65.6)$ & $56(29.2)$ & $10(5.2)$ & $0(0.0)$ \\
Urgency & $55(27.1)$ & $30(54.5)$ & $22(40)$ & $3(5.4)$ & $0(0.0)$ \\
Pain in the bladder & $41(20.1)$ & $14(34.1)$ & $23(56.1)$ & $3(7.3)$ & $1(2.4)$ \\
Daytime frequency & $36(17.6)$ & $19(52.8)$ & $12(33.3)$ & $4(11.1)$ & $1(2.8)$ \\
Voiding symptoms & & & & & \\
Hesitancy & $14(6.9)$ & $8(57.1)$ & $3(21.4)$ & $3(21.4)$ & $0(0.0)$ \\
Straining & $8(3.9)$ & $4(50.0)$ & $3(37.5)$ & $1(12.5)$ & $0(0.0)$ \\
Interrupted stream & $27(13.2)$ & $17(63.0)$ & $9(33.3)$ & $1(3.7)$ & $0(0.0)$ \\
Incontinence & & & & & \\
Urge & $20(9.8)$ & $8(40.0)$ & $9(45.0)$ & $3(15.0)$ & $0(0.0)$ \\
Stress & $28(13.7)$ & $15(53.6)$ & $10(35.7)$ & $3(10.7)$ & $0(0.0)$ \\
Unexplained & $4(2.0)$ & $2(50.0)$ & $2(50.0)$ & $0(0.0)$ & $0(0.0)$ \\
Nocturnal enuresis & $2(1.0)$ & $1(50.0)$ & $1(50.0)$ & $0(0.0)$ & $0(0.0)$ \\
\hline
\end{tabular}

\section{Discussion}

Storage phase symptoms were frequently reported by participants in this study, the commonest of which was nocturia, defined in this study as the complaint of waking up to void one or more times at night ${ }^{1}$. This was reported by about $95 \%$ of participants. In a cohort of Brazilian pregnant women in their third trimester of pregnancy, Scarpa et al similarly reported a high prevalence of nocturia $(80.6 \%)$ in pregnancy $^{12}$. Defining nocturia as at least three night-time voids, Parboosingh and Doig reported a prevalence rate of nocturia of $66 \%$ among 873 apparently healthy antenatal women by the third trimester of pregnancy ${ }^{13}$. Cutner's finding of a nocturia prevalence rate of $23 \%$ among women undergoing termination of pregnancy at 6-15 weeks gestational age $^{14}$, shows that the prevalence rate of nocturia may not vary only with the definition adopted but with the gestational age of pregnancy. In this study the prevalence of nocturia varied from $88.9 \%$ in the first trimester of pregnancy to $94.6 \%$ in the third trimester. Next to nocturia, urgency was also a frequent finding in this study being reported by 27.1 $\%$ of study participants. Cutner et al reported an urgency prevalence of $62 \%$ in their study ${ }^{14}$, while Chaliha et al reported a prevalence of $22.9 \%$ of urgency in pregnancy ${ }^{15}$.

Another filing/ storage phase symptom found in this study was frequency which was reported among $17.6 \%$ of the subjects. This varied from 22.2 percent in the first trimester to $12.9 \%$ in the third. In Cutner's study, up to $40 \% \mathrm{f}$ the subjects reported frequency ${ }^{14}$, while Scarpa et al reported that $70.3 \%$ of their study subjects had frequency ${ }^{12}$. Even though these rates vary for various reasons, it is clear that frequency of urination is an often reported lower urinary tract symptom among antenatal clients.

Voiding symptoms were also reported among subjects in this study, with interrupted stream being the commonest of them. However in the study by Stanton et al, hesitancy was the commonest voiding symptom experienced, with $27 \%$ of the pregnant women experiencing it in the first 2 trimesters of pregnancy, much higher than the finding of our study ${ }^{16}$.

The prevalence of urinary incontinence among this pregnant population was $26.5 \%$, with stress urinary incontinence being responsible for more than half of the cases of incontinence reported. Kristiansson and colleagues conducted a longitudinal, observational and prospective study of 200 women attending ANC in early pregnancy and found that the prevalence of stress urinary incontinence stabilized at $25 \%$ in mid-pregnancy among the subjects in that study ${ }^{17}$. In this study however, by mid-pregnancy, the prevalence rate of stress urinary incontinence was $12.9 \%$, about half of the findings of Kristiansson et al in a mainly Caucasian population. Burgio et al assessed urinary symptoms in a racially mixed sample and found that more white women reported incontinence as compared to black women to a statistically significant level, and also showed that the difference was likely attributable to the higher 
prevalence of stress incontinence among white women ${ }^{18}$. Even among non-pregnant women, some studies have found that African-American women were less likely to be diagnosed with stress incontinence than were Hispanic or white women ${ }^{19}$, 20

Urge incontinence was also reported by study participants in the second and third trimesters of pregnancy, with none in the first trimester. In the study by Cutner et al earlier cited, the prevalence of urge incontinence was found to be $18 \%{ }^{14}$, while Chaliha et al reported a prevalence rate of $8 \%$ for urge incontinence in pregnancy ${ }^{15}$. These show that the findings of the levels of urge incontinence in this study are comparable to that found among white pregnant women.

The absence of stress and urge incontinence in the first trimester of pregnancy would suggest that the physiological and anatomical changes in pregnancy that predispose to incontinence occur later in pregnancy. This finding is consistent with the findings by Viktrup et al that all lower urinary symptoms among their study subjects appeared late in the first trimester of pregnancy and worsened throughout pregnancy ${ }^{21}$.

The severity of these lower urinary symptoms varied among the study participants. For example, with about two-fifths of the subjects reporting that they would need to wake up 3-4 times each night, nocturia could be a troublesome and irritating symptom for many women. Among the subjects that reported stress incontinence, 3.6\% said that they had it most of the time and this could also be troublesome. Yamazaki found out among his study subjects that in $6.3 \%$ of them ${ }^{22}$, urinary incontinence was so severe that they needed to change their underwear often. Such a finding emphasizes the need to identify such women and take steps to address their irritating lower urinary tract symptoms.

This study shows that many pregnant women in Nigeria suffer in silence from a variety of lower urinary tract symptoms, at levels comparable to their counterparts in other parts of the world. They may not however have access to the level of care that their counterparts have. There is need to create awareness among health care providers on the lower urinary tract related morbidities in pregnancy and build their capacity to recognize, investigate and manage these symptoms.

\section{Conclusion}

Even though pregnant women in Zaria rarely complain about lower urinary tract symptoms, they are prevalent and diverse as seen among this antenatal population. Lack of uniformity in terminologies and their definitions, and the lack of standardised research tools have for many years hindered studies of female lower urinary symptoms. However, as seen in this study, the current definitions of lower urinary symptoms which are more research-friendly and the ICIQ-FLUTS questionnaire used in this study provide opportunities for research to understand and manage lower urinary symptoms in our female population. Furthermore, the questionnaire should be useful in the objective preoperative and postoperative assessment of cases of lower urinary tract symptoms in this setting.

\section{Acknowledgements}

The authors would like to thank the ICIQ study group for permission to use the ICIQ-FLUTS questionnaire for this study.

\section{References}

1. Abrams P, Cardozo L, Fall M, Griffiths D, Rosier P, Ulmstein U. The standardization of terminology of lower urinary tract function; report from the standardization sub-committee of the international continence society. Neurourol Urodyn 2002;21:167-78.

2. Al-Hayek P, Abrams P. Women's lower urinary tract function and dysfunction: definitions and epidemiology. Minerva Ginecol 2004;56:311-25.

3. Fitzgerald MP, Graziano S. Anatomical and functional changes of the lower urinary tract during pregnancy. Urologic Clinics of North America 2007;34:7-12.

4. Mikhail MS, Anyaegbunam A. Lower urinary tract dysfunction in pregnancy: a review. Obstet Gynecol Surv 1995;50:675-83.

5. Chaliha C, Stanton S. Urological problems in pregnancy. BJU Int 2001;89:469-76.

6. Malpas P, Jeffcoate TNA, Lister UM. Displacement of the bladder and urethra in late pregnancy. J Obstet Br Emp 1949;56:94960.

7. Thorp JM, Norton PA, Wall LL, Kuller JA, Euker B, Wells E. urinary incontinence in pregnancy and the puerperium: a prospective study. Am J Obstet Gynaecol 1999;181:266-73.

8. Aslan D, Aslan G, Yamazhan M, Ispahi C, Tinar S. Voiding symptoms in pregnancy: an 
assessment with international prostate symptom score. Gynecol Obstet Invest 2003;55:46-9.

9. Sun MJ, Chen GD, Chang SY, Lin KC, Chen SY. Prevalence of lower urinary tract symptoms during pregnancy in Taiwan. J Formos Med Assoc 2005;104:185-9.

10. Abrams P, Avery K, Gardener N, Donovan J. The International Consultation on Incontinence Modular Questionnaire:www.iciq.net. J Urol 2006;175:1063-6.

11. Avery K, Donovan J, Peters TJ, Shaw C, Gotoh M, Abrams P. ICIQ: A brief and robust measure for evaluating the symptoms and impact of urinary incontinence. Neurourol Urodyn 2004;00:1-9.

12. Scarpa KP, Hermann V, Palma PC, Ricetto CL, Morais S. Prevalence of urinary symptoms in the third trimester of pregnancy. Revista da Associacao Medica Brasileira 2006;3:153-6.

13. Parboosingh J, Doig A. Studies of nocturia in normal pregnancy. J Obstet Gynaecol Br Commonw 1973;80:888-95.

14. Cutner A, Cardozo LD, Benness CJ. Assessment of urinary symptoms in early pregnancy. $\mathrm{BrJ}$ Obstet Gynaecol 1991;98:1283-6.

15. Chaliha C, Kalia V, Stanton SL, Monga A, Sultan $\mathrm{AH}$. Antenatal prediction of postpartum urinary and fecal incontinence Obst Gynaecol 1999;94:689-94.
16. Stanton SL, Kerr-Wilson R, Harris GV. The incidence of urological symptoms in normal pregnancy. Br J Obstet Gynaecol 1980;87:897-900.

17. Kristiansson P, Samuelsson E, Von-Schoultz B, Svardsudd K. Reproductive hormones and stress urinary incontinence in pregnancy. Acta Obst Gynaecol Scand 2001;80:1125-30.

18. Burgio KL, Locher JL, Zyczynski H, Hardin JM, Singh K. Urinary incontinence during pregnancy in a racially mixed sample: characteristics and predisposing factors. Int Urogynecol J 1996;7:69-73.

19. Duong TH, Korn AP. A comparison of urinary incontinence among African-American, Asian, Hispanicn and white women. Am J Obstet Gynaecol 2001;184:1083-6.

20. Melville JL, Katon W, Delaney K, Newton K. Urinary Incontinence in US Women. Arch Intern Med 2005;165:537-42.

21. Viktrup L, Lose G, Rolf M, Barfoed K. The frequency of urinary symptoms during pregnancy and puerperium in the primipara. Int Urogynecol J 1993;4:27-30.

22. Yamazaki A. Urinary incontinence during pregnancy and after delivery. Shinshu Daigaku Iryo Gijutsu Tanki Daigakubu Kiyo 1999;25:218. 